\title{
Awake Craniotomy in High Risk for Failure Patient: Case Report
}

\author{
Quiroz Murga Eduardo*, Jaime Levy Ximena and Simon Scamarone Grassy \\ Department of Anesthesiology, Víctor Lazarte Echegaray Hospital of Trujillo, Perú
}

Submission: October 21, 2019; Published: October 28, 2019

*Corresponding author: Quiroz Murga Eduardo, Department of Anesthesiology, Víctor Lazarte Echegaray Hospital of Trujillo, Perú

\begin{abstract}
Awake craniotomy (AC) is a procedure that allows a functional mapping of the brain to achieve greater resection of the tumor with less neurological damage, the benefit being greater when it comes to eloquent areas. Proper patient selection will optimize the results. We present our experience in AC for a resection of brain tumor, suggestive of high-grade glioma, in a 74-year-old patient with dysphasia, right hemiparesis and convulsive syndrome in treatment with phenytoin. The technique used was awake-awake-awake, with the use of dexmedetomidine and remifentanil. Seizures occurred, which resolved quickly with direct instillation of saline and intravenous propofol. Despite being very beneficial and safe, it should be planned with all the actors involved and consider the neurological and pharmacological condition of the patient, as well as the possible perioperative complications.
\end{abstract}

Keywords: Awake craniotomy; Dexmedetomidine; Conscious sedation; Brain mapping; Brain tumor

\section{Introduction}

Awake craniotomy is a procedure that, from its first reports to the present, has been gaining ground due to the increasing availability of anesthetic agents with better safety profiles and the increase in surgical indications in which it can be used [1]. This procedure in the surgery of brain tumors is advantageous because the resection can be extended avoiding as much as possible the neurological damage. In order to opt for AC it is necessary, in addition to the skills of the surgical and anesthetic team, to make an adequate selection of the patient. The lack of cooperation and the failure in sedation could spoil the plan and opt for general anesthesia [2]. The case presented below corresponds to a challenge for us, due to the neurological damage it presents, as well as its age and the anticonvulsant treatment it received.

\section{Clinical Case}

A 74-year-old woman with high blood pressure and regular treatment with Losartan. Enter our hospital for complex focused seizures and dysphasia. Brain MRI shows a solid left frontal lesion with cystic and necrotic center, associated with extensive perilesional edema with mass effect, highly suggestive of high-grade glioma. It is programmed for tumor resection. In the preoperative stage, the patient received an evaluation for psychology and neurology, as well as the planned procedure and possible intraoperative events were also explained. She had no difficult airway predictors, she had a right hemiparesis with a crural predominance and a dysphasia that sometimes made communication difficult, but was possible. Apart from that, the patient was collaborative and obeyed orders. Laboratory tests within normal limits. From the date of admission, the patient received phenytoin IV 100mg every 8 hours. The medicine was not suspended. Patient enters awake, ventilating spontaneously and with urinary catheter. CVC 7 Fr was placed in the right internal jugular vein. Five lead electrocardiogram, pulse oximetry, $\mathrm{BIS}$, temperature and invasive BP were monitored. Antibiotic prophylaxis, $8 \mathrm{mg}$ of dexamethasone and $200 \mathrm{ml}$ of mannitol $20 \%$ were administered intravenously in coordination with the neurosurgeon. The awake-awake-awake technique was performed using dexmedetomidine. A loading dose was given for 10 minutes $(1 \mu \mathrm{g} / \mathrm{kg})$, followed by a maintenance infusion of $0.5 \mu \mathrm{g} / \mathrm{kg} / \mathrm{h}$. Ventilation and CO2 was monitored through a capnography line (EtCO2) attached to the oxygen mask and with arterial gas analysis.

The patient was then positioned supine with slight lateralization of the body to the right. Anesthetic blockade of the scalp and the areas of pin insertion was performed for cranial stabilization with the Mayfield. Neuronavigation was used for tumor delimitation and making the left pterional incision (Figure $1 \mathrm{~A} \& 1 \mathrm{~B})$. During trepanopuncture and removal of the bone, remifentanil was used as an adjuvant, at a target of $2-3 \mathrm{ng} / \mathrm{ml}$ at the 
effect - site. Later it was titled and withdrawn at the corresponding times (Figure 1C). The tumor area was delimited with cortical mapping and neuronavigation. The patient presented a seizure focused on the right upper limb, complex, after stimulation of the epileptogenic area. It was resolved with direct irrigation of saline solution and administration of 2 IV boluses of propofol $20 \mathrm{mg}$. With the help of the ultrasonic aspirator, approximately
$95 \%$ of the distinguishable tumor was removed (Figure 1D). The maintenance of conscious sedation was titrated and removed according to the surgical requirements and, prior to the closure of the skin, analgesia and preventive antiemetics were administered, to subsequently go to PACU awake and without pain. The patient went to the ICU for monitoring and was discharged two days later.

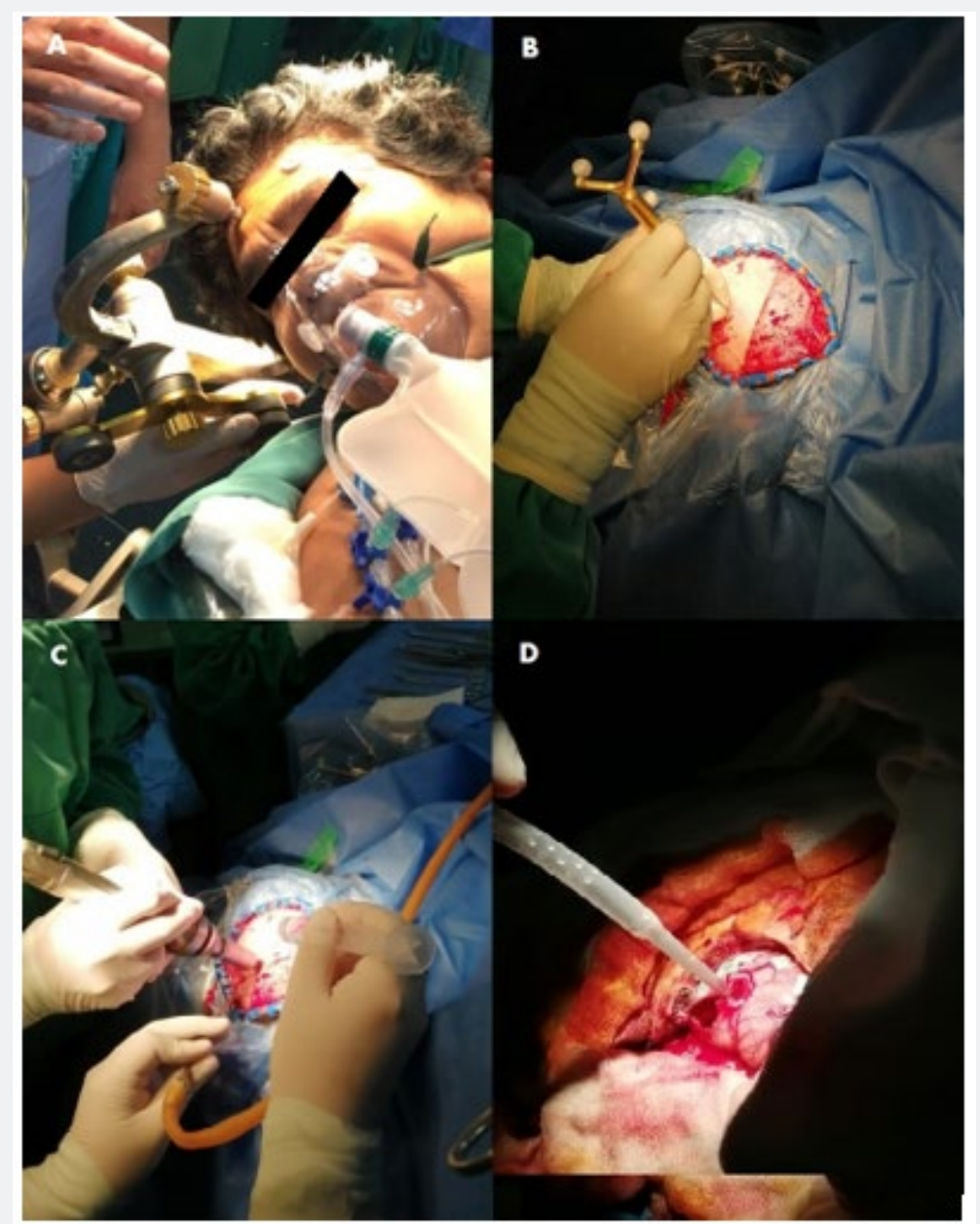

Figure 1: Four surgical moments with a patient under conscious sedation.

A. Mayfield placement.

B. Neuronavigation with cranial exposure.

C. Trepanotuncture.

D. Tumor resection with ultrasonic aspirator.

\section{Discussion}

$\mathrm{AC}$ is a long-standing procedure that initially focused on the mapping and removal of epileptogenic foci, however, currently its indications have been extended, as well as its use in different hospitals. Among the best known indications are stereotactic brain biopsy, ventriculostomy and resection of small brain lesions, mainly supratentorial location [1]. The decision to opt for AC is based on the results obtained against general anesthesia, that is, it maximizes tumor resection and minimizes neurological damage, especially in those patients with lesions near eloquent areas. Other benefits correspond to a faster recovery with less hospital stay, resource savings and patient satisfaction [3,4]. A recent meta-analysis by Gerritsen et al. [5] which included 53 studies with 9102 patients, compared AC and general anesthesia in surgeries of high - grade gliomas. The results were favorable towards the first, since a greater postoperative survival, lower 
postoperative complications and a higher percentage of resection were observed [5]. There are three techniques available for the development of AC: sleeping-awake-sleeping, awake-awakeawake and sleeping-awake-awake. The choice of technique is based on the preference of the neurosurgical team, their experience, patient profile and available resources. There is no superiority between them [2]. The success of the surgery depends on all the operators involved, including the selected patient. This must meet a series of requirements that make it a cooperative candidate and, after being informed, tolerate the procedure both by position, time, as well as possible inconvenience and adverse events. A preoperative psychological test and a preanesthetic evaluation were developed in our patient, who was cooperative and with good control of anxiety. The dysphasia and hemiparesis that she presented, in addition to her treatment with phenytoin, made this case a challenge, due to the risk of failure associated with it [6]. The anesthetic technique, awake-awake-awake, was chosen around her condition and our experience with the management of intravenous drugs.

The drug used was dexmedetomidine, an imidazole derivative of lipophilic character, with alpha 2 agonist action that has gained popularity in AC procedures for its properties as a sedative, analgesic, anxiolytic and for its minimal effects of respiratory depression. In addition, it has been suggested that dexmedetomidine maintains the coupling between the cerebral metabolic rate and cerebral blood Flow [7]. Remifentanil was used as an adjuvant for pain control at the surgical moments it merited. The close follow-up of surgery and communication with the team is essential for drug titration and hemodynamic management [8]. As a result of direct cortical stimulation, there was an episode of seizure, a complication that was resolved with direct irrigation of frozen saline and intravenous Propofol [1,2]. Seizures correspond to one of the most frequent complications in the context of AC. It varies between $9.3 \%$ and $18.5 \%$ in observational studies. They are usually focal and short-lived. Other possible complications are cerebral edema, tremors, airway obstruction, respiratory depression, pain, nausea and vomiting, air embolism and the trigeminocardiac reflex. Fortunately, there were no more complications during Surgery $[7,9,10]$. Nossek et al. [6] have reported, in a retrospective study, that the lack of intraoperative communication and intraoperative seizures have been the main causes of failure. In our case, the presence of seizures did not mean a failure, because after the postictal phase the evaluations continued, the completion of the brain mapping being possible and a large amount of tumor tissue resection was achieved [6].

\section{Conclusion}

The planning of the procedure is as important as its development, so that the proper selection of the patient, the consideration of their conditions, the communication, the choice of the anesthetic technique and a multidisciplinary team prepared, are indispensable to achieve success. The presence of predictors of failures should be considered for the contingency management of a complication and, if possible, conclude with tumor resection.

\section{Recommendations}

The development of strategies should also be oriented towards patients with neurological deficits that could benefit from this procedure. For these patients, contingency management protocols should be developed to reduce the failure rate.

\section{Informed Consent}

Provided freely by the patient.

\section{Acknowledgement}

The authors thank the neurosurgical team led by Dr. Humberto Elera Florez.

\section{Disclosures}

The financing of this work is with own resources.

The authors declare not to have any interest conflicts.

\section{References}

1. Özlü O (2018) Anaesthesiologist's Approach to Awake Craniotolmy. Turk J Anaesthesiol Reanim 46(4): 250-256.

1. Chui J (2015) Anestesia para craneotomía en el paciente despierto: una actualización. Anesthesia for awake craniotomy: An update. Revista Colombiana de Anestesiología 43(1): 22-28.

2. Gerritsen JKW, Viëtor CL, Rizopoulos D, Schouten JW, Klimek M, et al. (2019) Awake craniotomy versus craniotomty under general anesthesia without surgery adjuncts for supratentorial glioblastoma in eloquent áreas: a restrospective matched case-control study. Acta Neurochir (Wien) 161(2): 307-315.

3. Zelitzki R, Korn A, Arial E, Ben-Harosh C, Ram Z, et al. (2019) Comparison of Motor Outcome in Patients Undergoing Awake vs General Anesthesia Surgery for Brain Tumors Located Within or Adjacent to the Motor Pathways. Neurosurgery 85(3): 470-476.

4. Gerritsen JWK, Arends L, Klimek M, Dirven CMF, Vincent AJE (2019) Impact of intraoperative stimulation mapping on high-grade glioma surgery outcome: a meta-analysis. Acta Neurochir (Wien) 161(1): 99107.

5. Nossek E, Matot I, Shahar T, Barzilai O, Rapaport Y, et al. (2013) Failed awake craniotomy: a retrospective analysis in 424 patients undergoing craniotomy for brain tumor. J Neurosurg 118(2): 243-249.

6. McAuliffe N, Nicholson S, Rigamonti A, Hare GMT, Cusimano M, et al. (2018) Awake craniotomy using dexmedetomidine and scalp blockw: a retrospective cohort study. Can J Anaesth 65(10): 1129-1137.

7. Mohd Nazaruddin WH, Mohd Fahmi L, Laila AM, Zamzuri I, Abdul Rahman IZ, et al. (2013) Awake Craniotomy: A Case Series of Anaesthetic Management using a Combination of Scalp Block, Dexmedetomidine and Remifentanil in Hospital Universiti Sains Malaysia. Med J Malaysia 68(1): 64-66.

8. Mahajan C, Rath GP, Singh GP, Mishra N, Sokhal S, et al. (2018) Efficacy and safety of dexmedetomidine infusión for patients undergoing awake craniotomy: An observational study. Saudi J Anaesth 12(2): 235-239.

9. Sokhal N, Rath GP, Chaturvedi A, Dash HH, Bithal PK, et al. (2015) Anaesthesia for awake craniotomy: A retrospective study of 54 cases. Indian J Anaesth 59(5): 300-305. 
CC (1) This work is licensed under Creative
Your next submission with Juniper Publishers will reach you the below assets

- Quality Editorial service

- Swift Peer Review

- Reprints availability

- E-prints Service

- Manuscript Podcast for convenient understanding

- Global attainment for your research

- Manuscript accessibility in different formats

( Pdf, E-pub, Full Text, Audio)

- Unceasing customer service

Track the below URL for one-step submission

https://juniperpublishers.com/online-submission.php 